\title{
The Development of Conductive Nanoporous Chitosan Polymer Membrane for Selective Transport of Charged Molecules
}

\author{
Pei-Ru Chen and Yun-Ju Chuang \\ Department of Biomedical Engineering, Ming Chuan University, 5 De Ming Road, Gui Shan District, Taoyuan County 333, Taiwan \\ Correspondence should be addressed to Yun-Ju Chuang; yunju.chuang@gmail.com
}

Received 23 October 2012; Accepted 19 December 2012

Academic Editor: Woo Lee

Copyright (c) 2013 P.-R. Chen and Y.-J. Chuang. This is an open access article distributed under the Creative Commons Attribution License, which permits unrestricted use, distribution, and reproduction in any medium, provided the original work is properly cited.

\begin{abstract}
We present the development of conductive nanoporous CNT/chitosan membrane for charge-selective transport of charged molecules, carboxylfluorescein (CF), substance P, and tumor necrosis factor-alpha (TNF- $\alpha$ ). The membrane was made porous and conductive via gelatin nanoparticle leaching technique and addition of carbon nanotubes, respectively. These nanoporous membranes discriminate the diffusion of positive-charged molecules while inhibiting the passage of negative-charged molecules as positive potential was applied. The permeation selectivity of these membranes is reversed by converting the polarity of applied potential into negative. Based on this principle, charged molecules (carboxylfluorescein, substance P, and TNF- $\alpha$ ) are successfully filtered through these membranes. This system shows 30 times more selective for CF than substance P as positive potential was applied, while 2.5 times more selective for substance $\mathrm{P}$ than $\mathrm{CF}$ as negative potential was applied.
\end{abstract}

\section{Introduction}

Molecular transport through membrane containing nanopores or nanochannels has drawn much attention during recent years. There are many applications, such as separation and purification of protein, biomolecule detection and drug delivery, have been developed with nanopore structures that can offer high selectivity based on the interaction between molecules and nanopores [1-3]. Artificial nanoporous polymer membranes have been widely employed for the diffusion, separation, and discrimination of biomolecules [4-14]. The transport selectivity of molecules, based on the chemical and physical properties, was observed through porous membrane as the pore's size is sufficiently small that interactions between the pore surface and permeant molecules affect local transport dynamics. Traditionally, nanoporous membranebased separations simply utilize the difference in size of the analytes relative to pore size in the membrane. When using membranes for biomolecular separations, selectivity is typically achieved through control over membrane pore size relative to the size of the biomolecules that are being separated [15]. Current research and development of nanoporous membrane, in order to bring about selectivity beyond size, focuses on improvements in selectivity based on their charge [16]. As most of the biomolecules have their own charge, using charged membranes will provide additional flexibility to improve the selectivity of separation. A positively charged membrane will give higher retention of a positively charged biomolecule than will a negatively charged or neutral membrane of the same pore size [17]. The enhanced separations based on biomolecular properties such as charge, in addition to size, can also be achieved even though they have similar sizes. Martin et al. employed gold nanotubule polymer membranes, which are essentially an array of nanochannels, for ion separation [18], detection [19], and sizing [11]. They have successfully demonstrated the charge-dependent molecular transport and separation of enantiomeric drug [13]. Stroeve et al. demonstrated that the self-assembled functional molecules on these nanotubes can be used for the $\mathrm{pH}$-responsive transport of ions and protein analytes through nanoporous membranes $[14,20]$. $\mathrm{Ku}$ and Stroeve [21] demonstrated the selectivity of separation of two proteins with similar size in nanoporous membrane. The selectivity of similar proteins was achieved 
by modifying the surface charge of porous membrane to control protein transport [21]. Cheow et al. reported the selective transport of three differently charged proteins across a conductive nanoporous alumina membrane under varying potentials applied across the membrane [22]. Nguyen et al. developed a synthetic nanoporous membrane for chargeselective transport of ionic molecules via control of surface charge properties. The negatively charged membrane allows the selective transport of positively charged molecules while inhibiting the passage of negatively charged ones and vice versa [23].

In this research, we aim to develop and design an alternative strategy that enables the facile and flexible control of surface charge by directly applying electrical potential on the nanoporous membrane. In order to fulfill the requirement, we developed a conductive nanoporous membrane composed of chitosan and carbon nanotubes (CNTs). Chitosan, (1-4)-2-amino-2-deoxy- $\beta$-D-glucan, is the $\mathrm{N}$-deacetylated derivative of chitin, which is the structural element in the exoskeleton of crustaceans (crabs, shrimp, etc.). Chitosan has low toxicity and is hydrophilic, elastic, and biocompatible. Besides, chitosan can provide good mechanical strength for the formation of thin nanoporous membrane [24]. And also the gelatin nanoparticle leaching technique was employed to form nanoporous membrane. The gelatin nanoparticle was used as porogen and then digested it by gelatinase to form nanopores in chitosan/CNT composite membrane. In our case, as positive electrical potential was applied on the membrane, the surface of nanopores presents positive charge and then the membrane only allows the transport of negatively charged ions and molecules while rejecting cations. The surface charge and permeation selectivity of porous membrane were reversed by directly reversing the polarity of applying electrical potential. The negative charged membrane is selective for positively charged molecules because the negative electrical potential imports negative charge to the surface of nanopores. The scheme of selective transport of charged molecules is shown in Figure 1. Furthermore, our approach successfully demonstrated the charge-selective transport of organic and protein molecules.

\section{Experiments}

2.1. Preparation of Conductive Nanoporous Membrane. In this study, the fabrication of conductive nanoporous chitosan membrane was started with preparation of gelatin nanoparticles. The gelatin nanoparticles were prepared by method of twice desolvation. First, gelatin type A $(1.25 \mathrm{~g})$ was dissolved in $25 \mathrm{~mL}$ water under heating. In order to achieve the desolvation and rapid sedimentation of the gelatin, $25 \mathrm{~mL}$ of acetone was added to this solution. The supernatant consisted of some desolvated gelatin as well as gelatin in solution and was discarded. The remaining sediment was redissolved in $25 \mathrm{~mL}$ of water under heating and the $\mathrm{pH}$ value of solution was adjusted to 2.5. The gelatin solution was then desolvated again by dropwise addition of $40 \mathrm{~mL}$ acetone. After $10 \mathrm{~min}$ of stirring, $500 \mu \mathrm{L} 8 \mathrm{wt} \%$ glutaraldehyde solution was added to cross-link the gelatin nanoparticles. Then, adding gelatin nanoparticles as porogen into $2 \mathrm{wt} \%$ chitosan solution (deacetylated $>95 \%$, M.W. 300,000 Da) prepared in $0.1 \mathrm{M}$ acetic acid is to form chitosan/gelatin mixed solution. Multiwall carbon nanotubes were prepared on another silicon substrate by thermal chemical vapor deposition technique. The thermal CVD process can be summarized in two main steps. First, nickel (Ni) catalyst islands are formed on a silicon substrate through the sintering of a thin $\mathrm{Ni}$ film $(10 \mathrm{~nm})$ at $800^{\circ} \mathrm{C}$. Second, CNTs grow from the discrete catalyst islands in an atmosphere consisting of $\mathrm{NH}_{3}$ and $\mathrm{C}_{2} \mathrm{H}_{4}$ at flow rates of 90 and $30 \mathrm{sccm}$, respectively, at temperature of $800^{\circ} \mathrm{C}$ for 5 mins, and then turn off all gases and stay for 5 mins at $800^{\circ} \mathrm{C}$. Then, the chitosan and gelatin nanoparticles mixed solution was poured onto the CNTs substrate cast in petridish and then dried by heat in oven. Heat-dried membranes were prepared by allowing the solvent to evaporate at $50^{\circ} \mathrm{C}$ for $24 \mathrm{hrs}$. Then, all of the dried samples were immersed into $1 \mathrm{M}$ of $\mathrm{NaOH}$ solution for $2 \mathrm{hrs}$. These membranes were removed from $\mathrm{NaOH}$ solution and completely washed by distilled water. Then these membranes were transferred into $0.2 \%$ gelatinase solution at $37^{\circ} \mathrm{C}$ for $24 \mathrm{hrs}$. Finally, the nanoporous chitosan membranes were lyophilized overnight and completed the fabrication processes.

\subsection{Characterization of Conductive Nanoporous Membrane.} The morphological assessment of the nanoparticles was carried out by high-resolution field emission scanning electron microscope and transmission electron microscope. The electrical conductivity of nanoporous membrane was measured by four-point probes. Morphology and microstructure of conductive nanoporous membrane were observed using a field emission scanning electron microscope.

2.3. Permeation of Conductive Nanoporous Membrane. In order to verify that the conductive nanoporous membrane is permeable, permeation studies were performed using sideby-side diffusion cells and the experimental setup is shown in Figure 2. Preswollen conductive nanoporous membranes were mounted between the two half-cells of the donor cell and receptor cell without applying electrical potential. A solution with a specific concentration was added to the donor cell, and fresh buffer solution was added to the receptor cell. 3, 10, and $40 \mathrm{kDa}$ dextran fluorescein were used as model molecules for permeation studies. The receptor compartment was filled with $13 \mathrm{~mL}$ of $\mathrm{pH} 7.4$ PBS buffer while the donor compartment was filled with an equal volume of $0.1 \mathrm{mg} / \mathrm{mL}$ dextran fluorescein solution. At each time point, a $100 \mu \mathrm{L}$ sample solution was taken from the receptor cell, analyzed, and then returned to its compartment. Dextran fluorescein solution was determined by using fluorescence spectrophotometer.

2.4. Selective Permeation of Charged Molecules. For the selective diffusion of charged molecules, the conductive nanoporous membrane was mounted between the two halfcells (as shown in Figure 2) under application of electrical potential between +5 and -5 volts on the membrane. Carboxylfluorescein $(\mathrm{CF})$, substance $\mathrm{P}$, and tumor necrosis factor-alpha (TNF- $\alpha)$ were used for selective diffusion of 


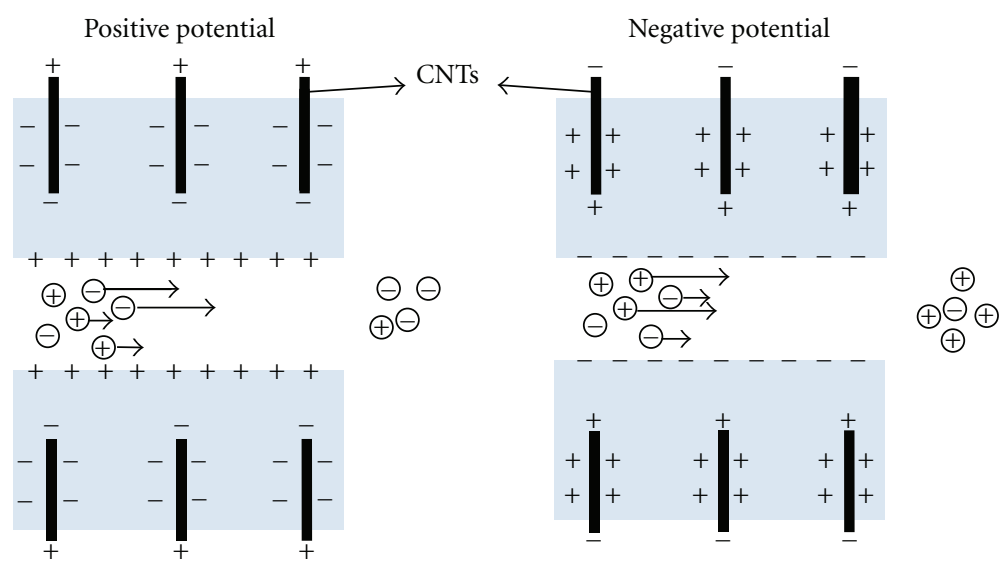

FIGURE 1: Scheme of selective transport in nanoporous membrane.

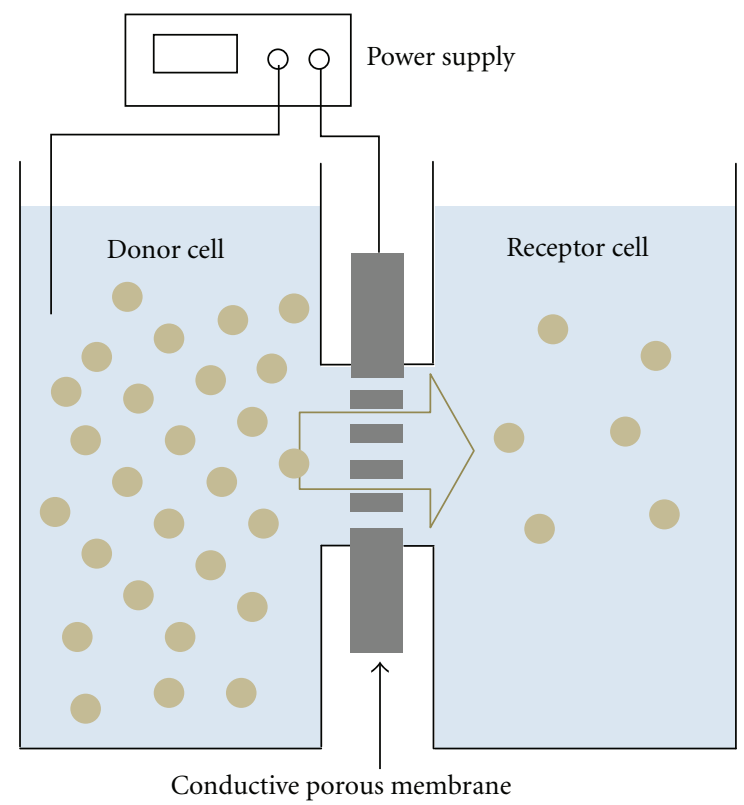

FIGURE 2: Schematic illustration of permeation cells for diffusion of charged analytes through conductive nanoporous membrane.

charged analytes and dissolved in pH 7.4 PBS buffer solution. The donor half-cell contained a known concentration of an analyte in the buffer solution, whereas the receptor half-cell was filled with pure PBS buffer solution. For mixed charged molecules diffusion, the concentration of charged analytes in the donor half-cell was chosen to be $6 \mu \mathrm{g} / \mathrm{mL}$. Both solutions in two half-cells were not stirred the whole process. After a preset time, $100 \mathrm{~min}$, the concentration of charged analyte in the receptor half-cell was determined by measuring the UV absorbance with a UV/vis spectrometer.

\section{Results and Discussions}

3.1. Characterization of Conductive Nanoporous Membrane. The SEM and TEM images of gelatin nanoparticles were shown in Figure 3. Inspection of the electron micrographs,

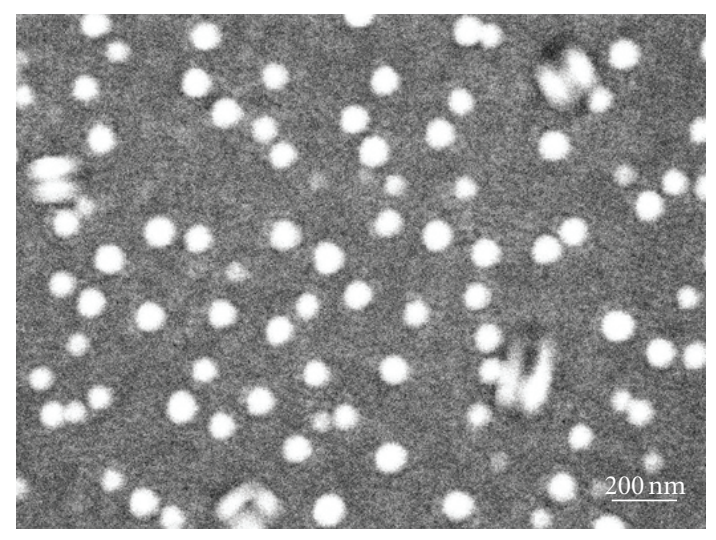

(a)

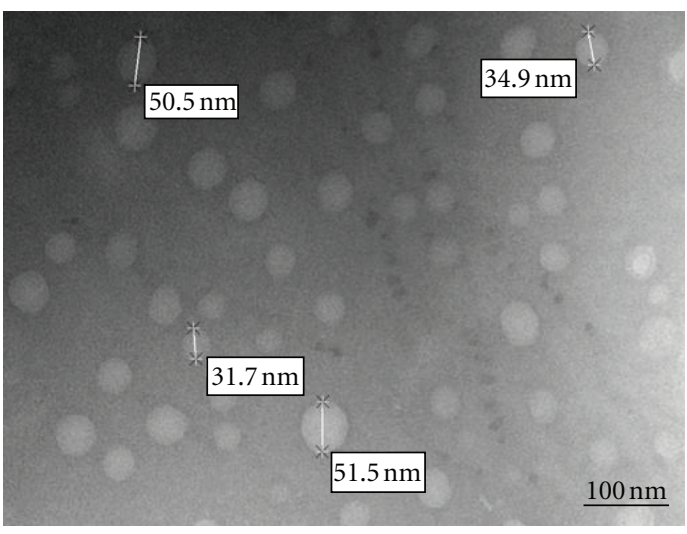

(b)

FIGURE 3: (a) SEM and (b) TEM images of gelatin nanoparticles.

the morphology of gelatin nanoparticles, was observed to be spherical and polydispersed. Furthermore, the size distribution of synthesized gelatin nanoparticles is narrow and the major size is between 45 and $70 \mathrm{~nm}$. The narrow size distribution can be attributed to the use of twice desolvation that can greatly reduce the production of nanoparticles with larger size. The scanning electron microscope images of conductive nanoporous membrane were shown in Figure 4. The SEM 


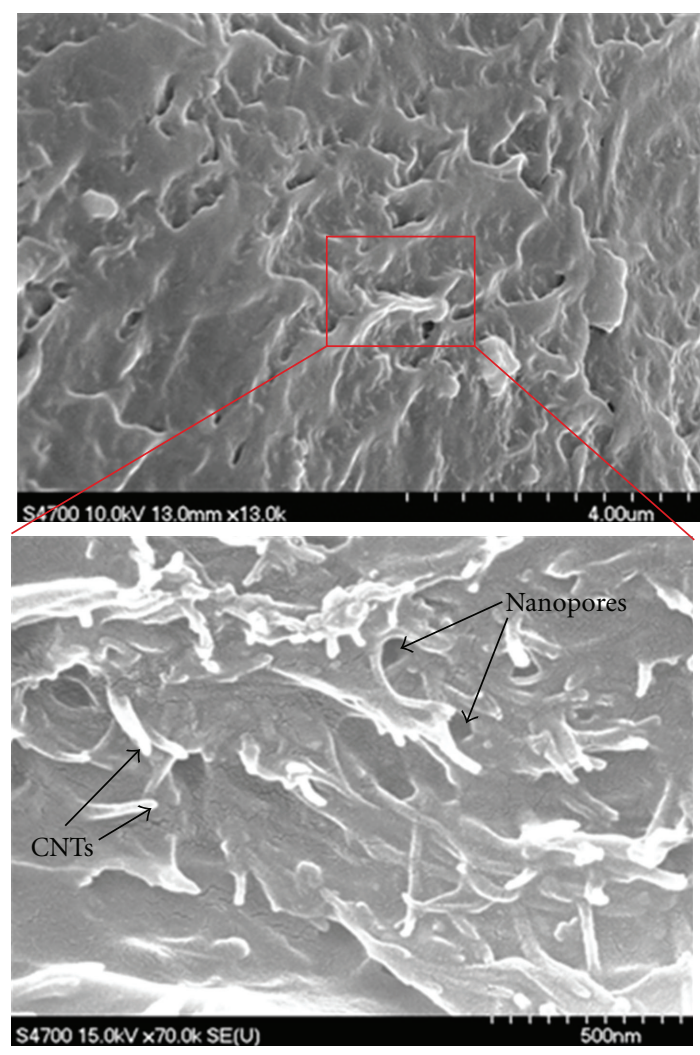

FIGURE 4: Scanning electron micrographs of conductive nanoporous membrane.

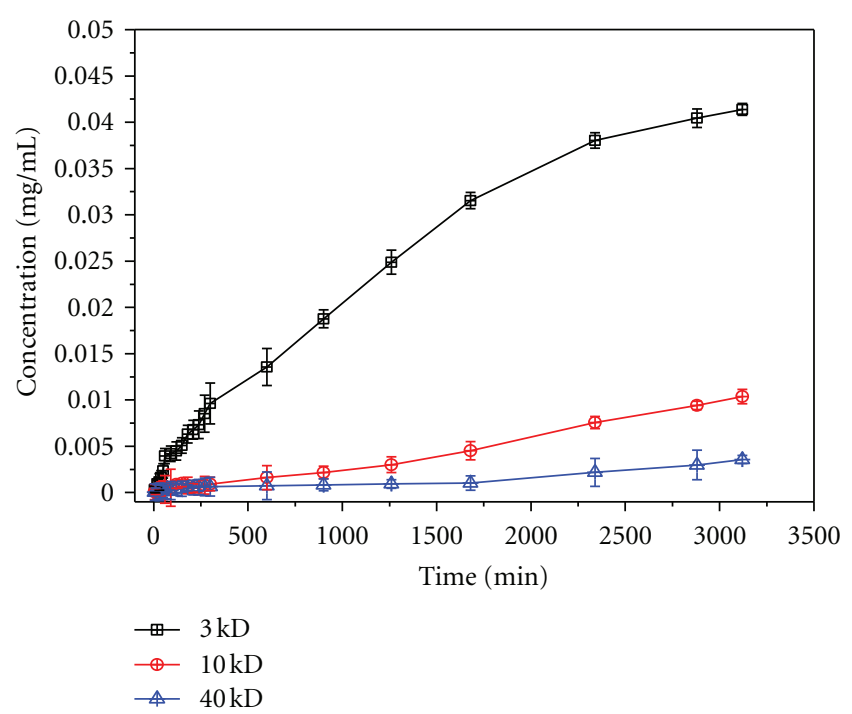

FIGURE 5: Permeation study of the nanoporous membrane with 3,10 , and $40 \mathrm{kDa}$ dextran fluorescein molecules without applying electrical potential.

images showed that the pore size of the nanoporous chitosan membrane is around 40 to $100 \mathrm{~nm}$ which is coincident with the size of gelatin nanoparticles and also we can find that the CNTs are dispersed in membrane without aggregation. The electrical conductivity of conductive nanoporous membrane was measured and the result showed that the sheet resistance

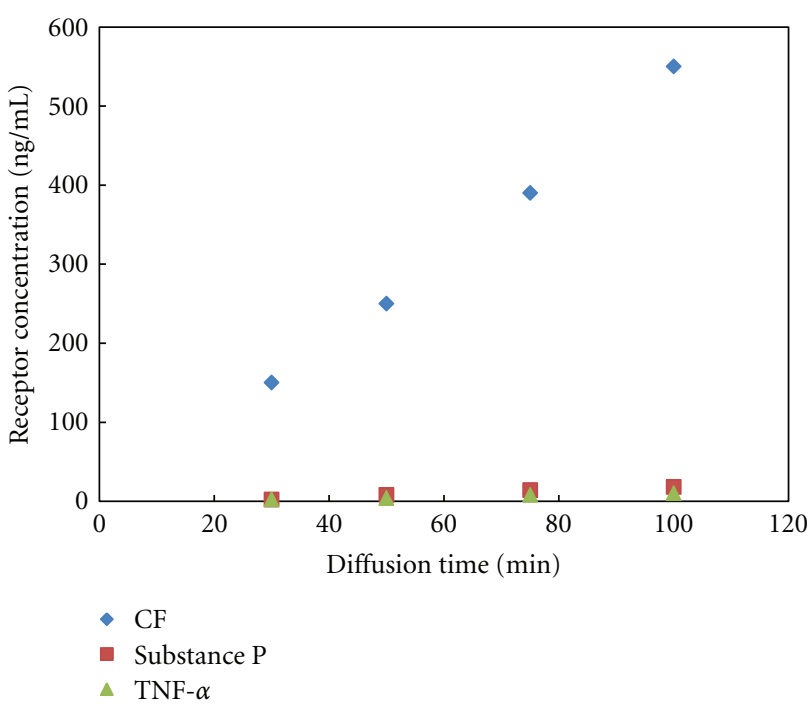

(a)

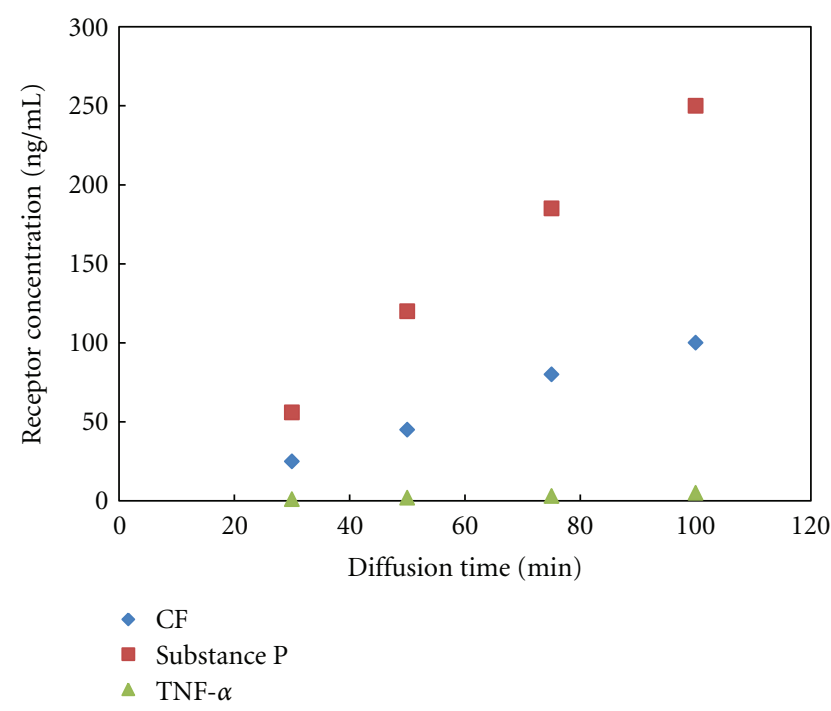

(b)

FIGURE 6: Diffusion of CF, substance P, and TNF- $\alpha$ at $\mathrm{pH} 7.4$ under (a) +5 volt and (b) -5 volt electrical potential applied on the conductive nanoporous membrane.

of membrane is $2.54 \pm 0.29 \mathrm{k} \Omega / \square$. This reveals that the nanoporous membrane with addition of CNTs is electrically conductive.

3.2. Permeation Characteristics of Nanoporous Membrane. Figure 5 showed the permeated concentration of dextran fluorescein molecules across the nanoporous membrane under zero electrical potential. After diffusion of $52 \mathrm{hrs}$, there were $41.39 \%$ of $3 \mathrm{kDa}$ dextran fluorescein molecules diffused or traversed across the nanoporous membrane. But for $10 \mathrm{kDa}$ and $40 \mathrm{kDa}$ dextran fluorescein molecules, only $10.38 \%$ and $3.58 \%$ can transport to the receptor half-cell. In addition, we used the permeability in $600 \mathrm{~min}$ to evaluate the cutoff size of nanoporous membrane. After $600 \mathrm{~min}$ of permeation study, 


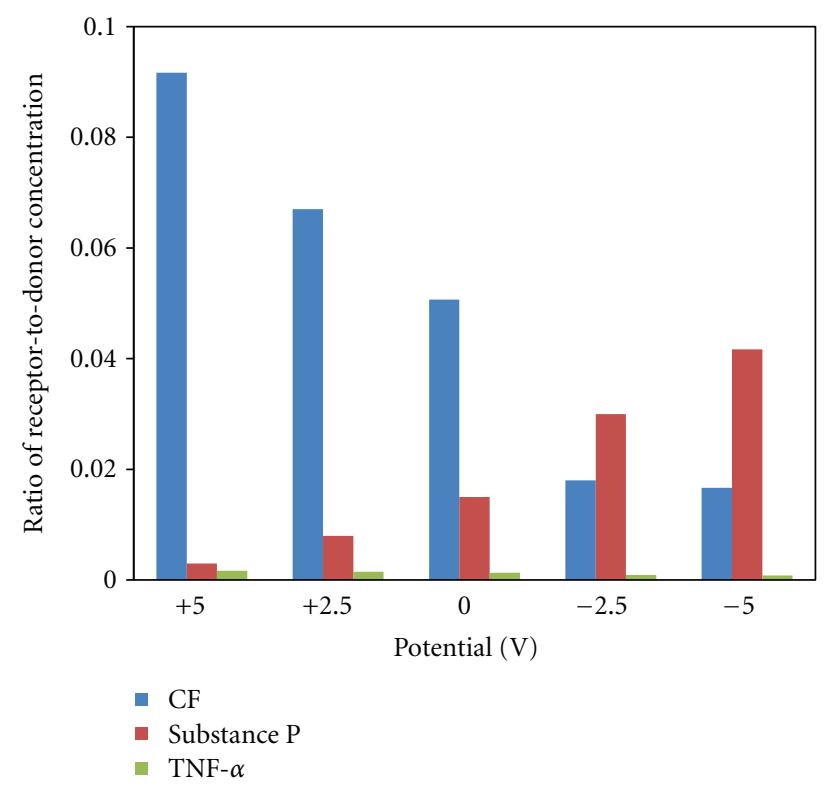

FIgURE 7: Ratio of receptor-to-donor concentration for CF, substance P, and TNF- $\alpha$ charged molecules at different electrical potential after 100 minutes diffusion. The donor cell contained a $1: 1: 1$ (CF: substance P:TNF- $\alpha$ ) mixture solution and the concentration was $6 \mu \mathrm{g} / \mathrm{mL}$.

the diffused amount of $3 \mathrm{kDa}$ dextran fluorescein molecules was reached to $13.5 \%$ through nanoporous membrane, but only $1.62 \%$ and $0.73 \%$ for $10 \mathrm{kDa}$ and $40 \mathrm{kDa}$ dextran fluorescein molecules. The results suggested that the cutoff size for this conductive nanoporous membrane is around $10 \mathrm{kDa}$.

3.3. Selective Permeation of Charged Molecules. The donor solution consisted of CF, substance P, and TNF- $\alpha$ mixture with equal concentration $(6 \mu \mathrm{g} / \mathrm{mL})$, buffered at $\mathrm{pH}$ 7.4. The electrical potential was applied on the conductive nanoporous membrane with reference to the donor halfcell side which was grounded. The concentration of charged molecules transported across the conductive nanoporous membrane as a function of time is plotted in Figure 6. It was observed that the receptor concentration of CF is higher than substance P and TNF- $\alpha$ at an electrical potential of $+5 \mathrm{~V}$ applying on the membrane. In contrast, at an electrical potential of $-5 \mathrm{~V}$, the receptor concentration of substance $\mathrm{P}$ is higher than CF and TNF- $\alpha$. Figure 7 compared the ratio of receptor to donor concentration for each kind of molecules at different electrical potential applied on the membrane. The ratio of receptor to donor concentration for $\mathrm{CF}$ and TNF- $\alpha$ increased with increasing positive potential. In contrast, the ratio of receptor to donor concentration for substance $\mathrm{P}$ increased with increasing negative potential. It showed that the CF and substance P molecules were most selective when positive and negative potential was applied, respectively. The ratio of receptor to donor concentration for all three molecules showed the largest differences at $+5 \mathrm{~V}$ in the experiment. At electrical potential of $+5 \mathrm{~V}$, the solution in receptor contained substance P:CF: TNF- $\alpha$ in the ratio of
$1: 30.5: 0.56$, while at electrical potential of $-5 \mathrm{~V}$, the ratio was $2.5: 1: 0.05$.

There are two major mechanisms that affect the molecules transport through the nanoporous membrane. The first is volume exclusion, and the other is electrostatic interaction. In our research, the nanoporous membrane selectively affects the charged molecules permeation via electrostatic interaction under the application of electrical potential on membrane. The electrostatic interaction between charged molecules in solution and fixed charge on the nanopores is responsible for the variation of ratio of receptor to donor concentration for substance P, CF and TNF- $\alpha$.

At pH 7.4 buffer solution, CF, substance P, and TNF$\alpha$ exist as an anion, cation, and anion, respectively. The net charges of CF, substance P, and TNF- $\alpha$ are $-3,+1.76$, and -0.89 , and their molecular weights are $0.376,1.347$, and $17.4 \mathrm{kDa}$, respectively. Thus, CF and TNF- $\alpha$ anions diffused more rapidly through the membrane at positive potential than at negative potential. In contrast, the permeated substance $\mathrm{P}$ cations were favored at negative potential as compared to positive potential. From the results of membrane permeation characteristics, the cutoff molecular weight was around $10 \mathrm{kDa}$. The molecular weight of TNF- $\alpha$ is larger than the cutoff molecular weight of membrane and caused it more difficult to diffuse through the membrane and lead to lowest ratio of receptor-to-donor concentration. In addition, due to the lower molecular weight and higher net charges of CF compared to substance $\mathrm{P}$, the CF molecules can move more freely in the nanoporous membrane. As a consequence, the ratio of CF to substance $\mathrm{P}$ in receptor solution at $+5 \mathrm{~V}$ electrical potential, 30.5 , is much higher than the ratio of substance $\mathrm{P}$ to $\mathrm{CF}$ in receptor solution at $-5 \mathrm{~V}$ electrical potential, 2.5 .

\section{Conclusions}

In this work, an electrically conductive nanoporous membrane was developed and employed for the separation of three different molecules. We showed the capability of varying the selectivity for different charged molecules by a direct and simple method to control the surface charge properties of conductive nanoporous membranes via applying electrical potential. We have demonstrated that the negatively charged membranes allow the selective transport of positively charged molecules and repelled the passage of negatively charged ones. The selectivity of these filters was reversed by changing the electrical potential from negative to positive. Therefore, this platform can efficiently filter and discriminate electrically charged molecules and suggests potential applications on the separation of other mixtures of organic and biomolecules.

\section{Acknowledgment}

The authors would like to thank the National Science Council of Taiwan for the financial support under the Contract no. of NSC 101-2221-E-130-011. 


\section{References}

[1] C. R. Martin and P. Kohli, "The emerging field of nanotube biotechnology," Nature Reviews Drug Discovery, vol. 2, no. 1, pp. 29-37, 2003.

[2] C. Dekker, "Solid-state nanopores," Nature Nanotechnology, vol. 2, no. 4, pp. 209-215, 2007.

[3] S. Majd, E. C. Yusko, Y. N. Billeh, M. X. Macrae, J. Yang, and M. Mayer, "Applications of biological pores in nanomedicine, sensing, and nanoelectronics," Current Opinion in Biotechnology, vol. 21, no. 4, pp. 439-476, 2010.

[4] S. B. Lee and C. R. Martin, "pH-switchable, ion-permselective gold nanotubule membrane based on chemisorbed cysteine," Analytical Chemistry, vol. 73, no. 4, pp. 768-775, 2001.

[5] C. R. Martin, M. Nishizawa, K. Jirage, and M. Kang, "Investigations of the transport properties of gold nanotubule membranes," Journal of Physical Chemistry B, vol. 105, no. 10, pp. 1925-1934, 2001.

[6] K. B. Jirage, J. C. Hulteen, and C. R. Martin, "Nanotubule-based molecular-filtration membranes," Science, vol. 278, no. 5338, pp. 655-658, 1997.

[7] R. Schmuhl, A. Van Den Berg, D. H. A. Blank, and J. E. Ten Elshof, "Surfactant-modulated switching of molecular transport in nanometer-sized pores of membrane gates," Angewandte Chemie International Edition, vol. 45, no. 20, pp. 3341-3345, 2006.

[8] C. R. Martin, M. Nishizawa, K. Jirage, M. S. Kang, and S. B. Lee, "Controlling ion-transport selectivity in gold nanotubule membranes," Advanced Materials, vol. 13, no. 18, pp. 1351-1362, 2001.

[9] S. B. Lee and C. R. Martin, "Electromodulated molecular transport in gold-nanotube membranes," Journal of American Chemical Society, vol. 124, no. 40, pp. 11850-11851, 2002.

[10] J. C. Hulteen, K. B. Jirage, and C. R. Martin, "Introducing chemical transport selectivity into gold nanotubule membranes," Journal of the American Chemical Society, vol. 120, no. 26, pp. 6603-6604, 1998.

[11] K. B. Jirage, J. C. Hulteen, and C. R. Martin, "Effect of thiol chemisorption on the transport properties of gold nanotubule membranes," Analytical Chemistry, vol. 71, no. 21, pp. 4913-4918, 1999.

[12] M. Wirtz, S. F. Yu, and C. R. Martin, "Template synthesized gold nanotube membranes for chemical separations and sensing," Analyst, vol. 127, no. 7, pp. 871-879, 2002.

[13] S. B. Lee, D. T. Mitchell, L. Trofin et al., "Antibody-based bio-nanotube membranes for enantiomeric drug separations," Science, vol. 296, no. 5576, pp. 2198-2200, 2002.

[14] Z. Hou, N. L. Abbott, and P. Stroeve, "Self-assembled monolayers on electroless gold impart $\mathrm{pH}$-responsive transport of ions in porous membranes," Langmuir, vol. 16, no. 5, pp. 2401-2404, 2000.

[15] K. B. Jirage, J. C. Hulteen, and C. R. Martin, "Nanotubule-based molecular-filtration membranes," Science, vol. 278, no. 5338, pp. 655-658, 1997.

[16] R. Van Reis and A. Zydney, "Membrane separations in biotechnology," Current Opinion in Biotechnology, vol. 12, no. 2, pp. 208-211, 2001.

[17] A. Mehta and A. L. Zydney, "Effect of membrane charge on flow and protein transport during ultrafiltration," Biotechnology Progress, vol. 22, no. 2, pp. 484-492, 2006.
[18] M. Nishizawa, V. P. Menon, and C. R. Martin, "Metal nanotubule membranes with electrochemically switchable iontransport selectivity," Science, vol. 268, no. 5211, pp. 700-702, 1995.

[19] Y. Kobayashi and C. R. Martin, "Highly sensitive methods for electroanalytical chemistry based on nanotubule membranes," Analytical Chemistry, vol. 71, no. 17, pp. 3665-3672, 1999.

[20] K. Y. Chun and P. Stroeve, "Protein transport in nanoporous membranes modified with self-assembled monolayers of functionalized thiols," Langmuir, vol. 18, no. 12, pp. 4653-4658, 2002.

[21] J. R. Ku and P. Stroeve, "Protein diffusion in charged nanotubes: "On-Off" behavior of molecular transport," Langmuir, vol. 20, no. 5, pp. 2030-2032, 2004.

[22] P. S. Cheow, E. Z. C. Ting, M. Q. Tan, and C. S. Toh, “Transport and separation of proteins across platinum-coated nanoporous alumina membranes," Electrochimica Acta, vol. 53, no. 14, pp. 4669-4673, 2008.

[23] Q. H. Nguyen, M. Ali, V. Bayer, R. Neumann, and W. Ensinger, "Charge-selective transport of organic and protein analytes through synthetic nanochannels," Nanotechnology, vol. 21, no. 36, Article ID 365701, 2010.

[24] M. N. V. Ravi Kumar, "A review of chitin and chitosan applications," Reactive and Functional Polymers, vol. 46, no. 1, pp. 1-27, 2000. 

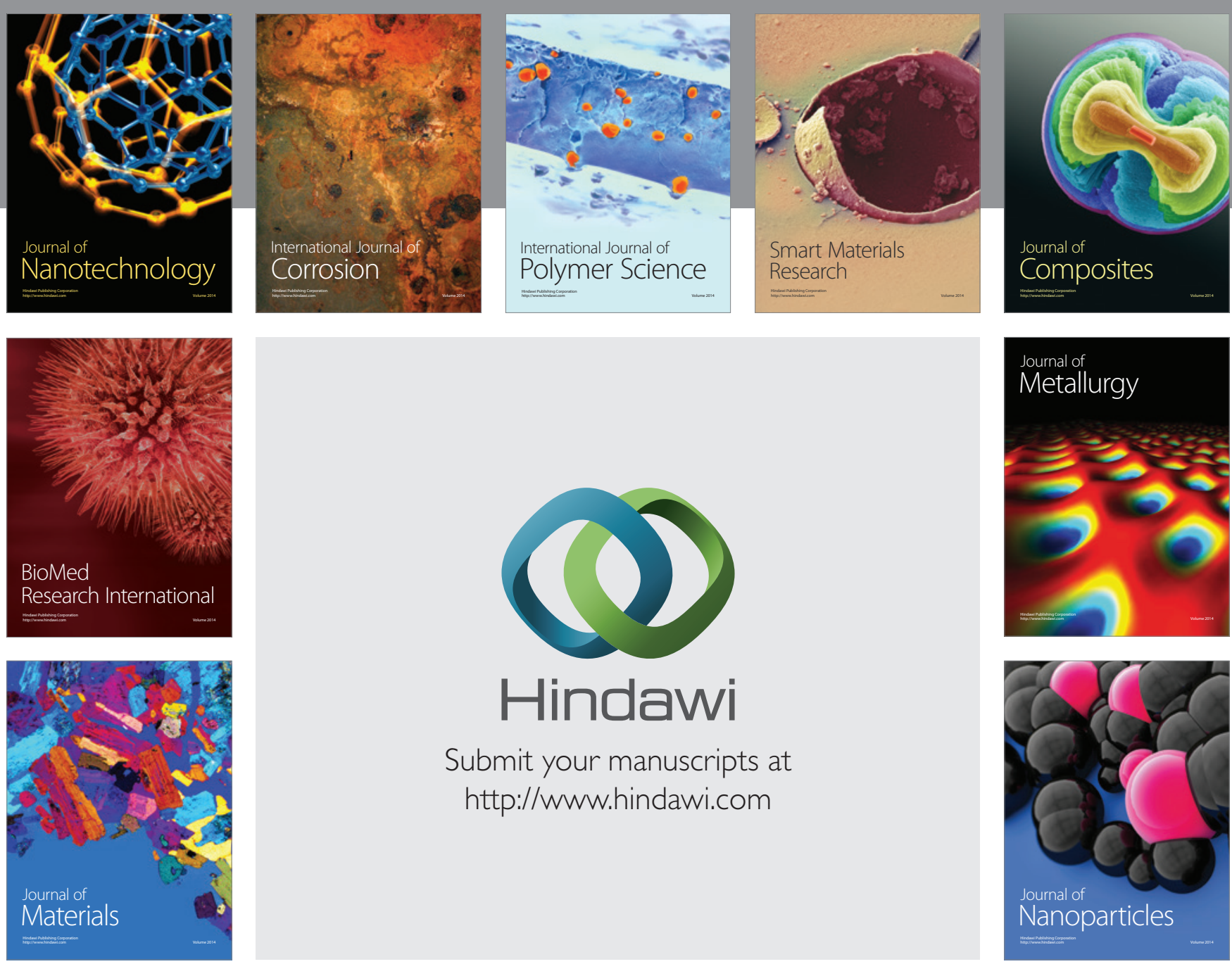

Submit your manuscripts at http://www.hindawi.com
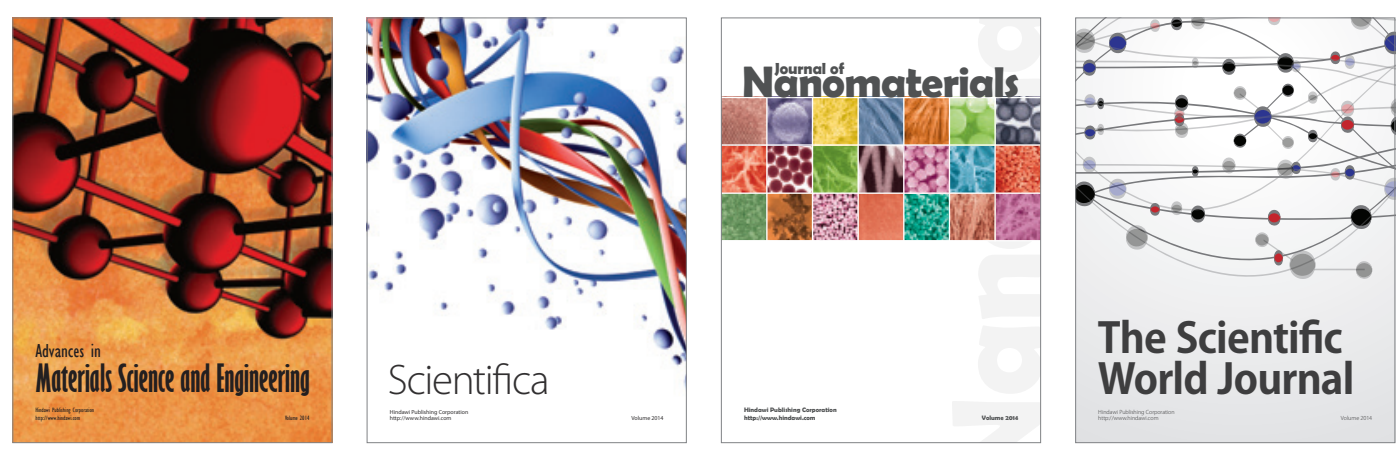

\section{The Scientific World Journal}
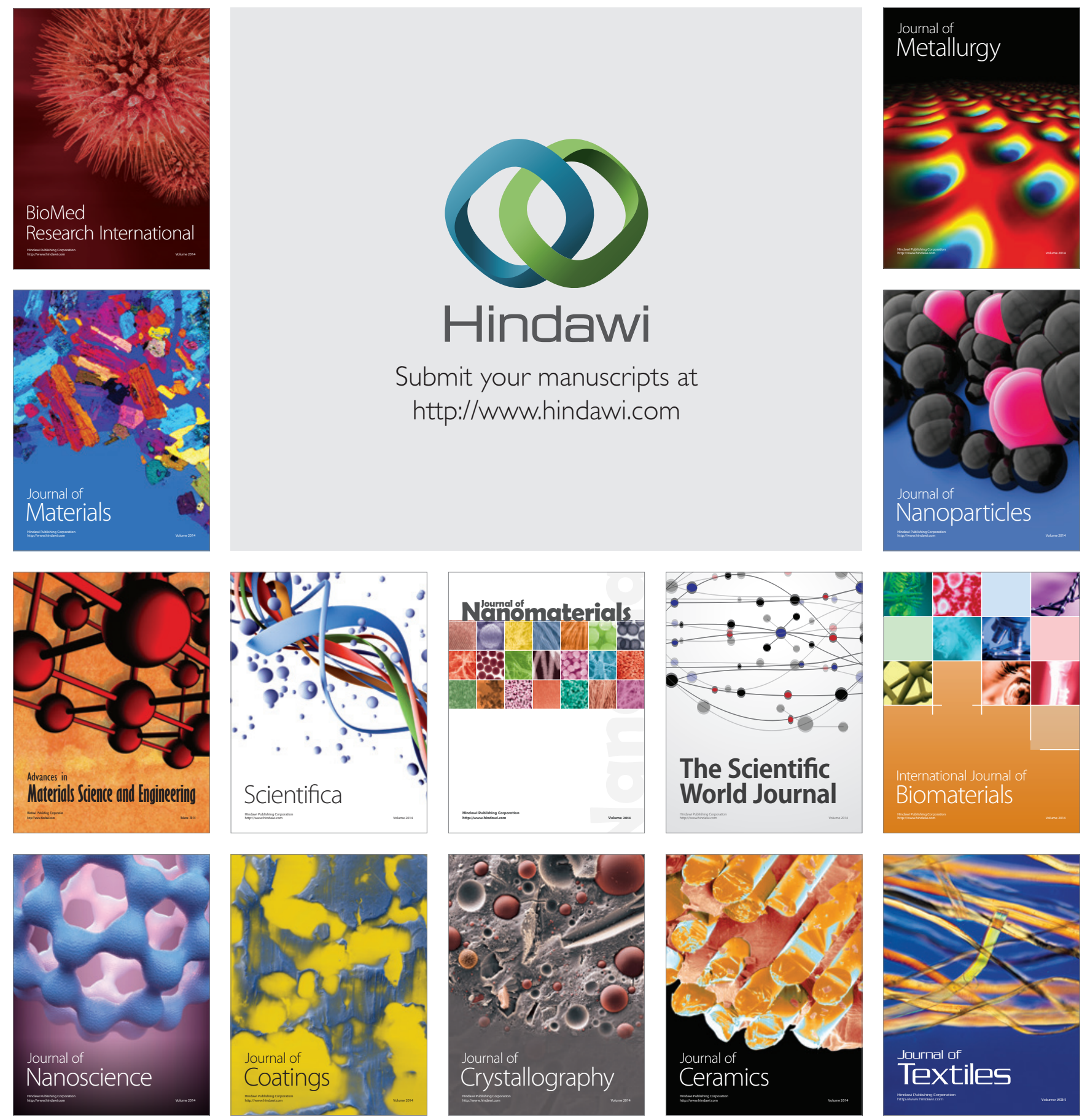